\title{
D-Cycloserine Increases Positive Symptoms in Chronic Schizophrenic Patients When Administered in Addition to Antipsychotics: A Double-Blind, Parallel, Placebo-Controlled Study
}

B. N. M. van Berckel, M.D., Ph.D., C. N. Evenblij, B. J. A. M. van Loon, M. F. Maas, M. A. M. van der Geld, M.D., H. J. Wynne, Ph.D., J. M. van Ree, Ph.D., and R. S. Kahn, M.D., Ph.D.

\begin{abstract}
A hypofunction of the glutamatergic system and NMDA receptors in schizophrenia has been hypothesized. Therefore, stimulation of these receptors could be of benefit to patients with schizophrenia. D-cycloserine has been used for this purpose. This study reports the effects of $100 \mathrm{mg} D$-cycloserine, when added to typical antipsychotics in chronic schizophrenic patients exhibiting prominent negative symptoms, using a placebo-controlled, double-blind, parallel, design. D-cycloserine slightly worsened psychotic symptoms and general psychopathology as compared to placebo. D-cycloserine failed to change negative symptoms and had no effect on extrapyramidal symptoms. The exacerbation of schizophrenic symptoms may be explained by the antagonistic effects of this dose of $D$-cycloserine at the glycine recognition site of the NMDA receptor due to
\end{abstract}

competition with the endogenous agonist glycine. Another explanation for the increase in psychopathology may be an interaction with the effects of antipsychotics on NMDA mediated neurotransmission. Thus, D-cycloserine in this study did not ameliorate schizophrenic symptoms.

However, the fact that they actually worsened suggests that NMDA systems may be involved in the pathogenesis of schizophrenia. Further placebo-controlled studies with lower dosages of $D$-cycloserine, preferably in drug-free patients, are necessary to evaluate if D-cycloserine is of use for the treatment of patients with schizophrenia.

[Neuropsychopharmacology 21:203-210, 1999] (C) 1999 American College of Neuropsychopharmacology. Published by Elsevier Science Inc.
KEY WORDS: Glycine; D-cycloserine; Schizophrenia; Glutamate; Luteinizing hormone

From the Department of Psychiatry, University Hospital Utrecht (BNMvB, CNE, BJAMvL, MFM, RSK) and the Rudolf Magnus Institute for Neurosciences (JMvR), the Centre for Biostatistics, University of Utrecht (HJW) Utrecht and Psychiatric Hospital. "Veldwyk" (MAMvdG) Ermelo, The Netherlands.

Address correspondence to: Bar N.M. van Berckel, M.D., Department of Psychiatry, University Hospital Utrecht, P.O. Box 85500, 3508 G.A., Utrecht, the Netherlands.

Received January 26, 1998; accepted November 10, 1998.
Excitatory amino acids, such as glutamate and asparate, and their receptors, like the N-methyl-D-aspartate (NMDA) receptor, have been suggested to be involved in several cerebral disorders, such as cerebral ischaemia (Paschen 1996) and schizophrenia (Javitt and Zukin 1991; Henn 1995; Olney and Farber 1995).

In schizophrenia, a role for excitatory amino acids and NMDA receptors was suggested when NMDA receptor antagonists, such as phencyclidine (PCP) and ketamine, were found to induce symptoms resembling the positive and negative symptoms of schizophrenia in 
healthy subjects and exacerbate such symptoms in patients with schizophrenia (Luby et al. 1962; Javitt and Zukin 1991; Krystal et al. 1994; Lahti et al. 1995; Malhotra et al. 1997b). A hypofunction of the glutamatergic system and NMDA receptors has been hypothesized in schizophrenia (for review, see Olney and Farber 1995) and appears to be supported by post-mortem studies (Nishikawa et al. 1983; Toru et al. 1988; Ishimaru et al. 1994; Tsai et al. 1995).

If schizophrenic symptoms are the result of the diminished functioning of NMDA receptors, stimulation of these receptors could be beneficial for patients with schizophrenia. Glycine and D-cycloserine stimulate the strychnine-insensitive glycine recognition site of the NMDA receptor and, by inference, may ameliorate schizophrenic symptoms. Some studies have used glycine for this purpose. In a double-blind, parallel, placebo-controlled study with seven patients in each group, glycine treatment during 8 weeks in a dose $\sim 30$ grams daily, added to typical antipsychotics, selectively reduced the scores on the negative symptom subscale of the Positive and Negative Symptoms Scale (PANSS) (Javitt et al. 1994). A similar result has also been reported in 11 schizophrenic patients using glycine in dosages between 40 and 80 grams daily in a doubleblind crossover design with treatment periods of 6 weeks (Heresco-Levy et al. 1996). These two studies suggest that stimulation of the NMDA receptor may ameliorate the negative symptoms of schizophrenia.

As a treatment of schizophrenic symptoms, glycine's major limitation is its limited access to the central nervous system (CNS). Contrary to glycine, the partial NMDA agonist D-cycloserine, an antibiotic used in the treatment of tuberculosis (Walker and Murdoch 1957), rapidly passes the blood-brain barrier and may therefore be more suitable for the treatment of patients with schizophrenia than glycine. However, D-cycloserine acts as a partial agonist of the NMDA receptor, with around $60 \%-90 \%$ of the agonistic efficacy of glycine (Chessell et al. 1991; Priestley et al. 1995) and with between 6 to 20 times less affinity for the glycine recognition site of the NMDA receptor than glycine (Ishimaru et al. 1994; Priestley et al. 1995). Thus, its effect on NMDA receptor activity may depend on the occupancy of the glycine binding site by (the endogeneous agonist) glycine: if this recognition site is not fully saturated in vivo, D-cycloserine may be expected to enhance the stimulating effects of the endogeneous glycine in low dosages while in high dosages D-cycloserine could reduce this effect, due to its competition with glycine. Therefore, the effects of D-cycloserine may be biphasic at different doses: agonistic at lower doses and antagonistic at higher doses.

Several studies using challenge paradigms found that the systemic administration of $3-20 \mathrm{mg} / \mathrm{kg}$ of D-cyclo- serine in rats exerts an agonistic effect on NMDA receptors using different models, like immediate early genes (Gao et al. 1997), second messenger response (Emmett et al. 1991), enhancement of TCP binding (Hood et al. 1980), facilitation of performance in learning tasks (Monahan et al. 1989; Quartermain et al. 1994). An agonistic effect of D-cycloserine is also suggested in human subjects using secretion of luteinizing hormone (LH) since preclinical studies indicate that $\mathrm{LH}$ secretion increases in response to NMDA receptor stimulation (van Berckel et al. 1998b). This suggests that the glycine recognition site of the NMDA receptor is probably not saturated in vivo in healthy subjects and that low dosages of D-cycloserine can indeed be used, as in animals, to stimulate human NMDA receptor activity. Thus, low dosages of D-cycloserine may be expected to be effective in the treatment of schizophrenia.

Two open, uncontrolled, dose-findings studies with D-cycloserine have been performed in patients with schizophrenia, either added to typical antipsychotics, using $5 \mathrm{mg}, 15 \mathrm{mg}, 50 \mathrm{mg}$, and $250 \mathrm{mg}$ D-cycloserine daily consecutively for 2 weeks (Goff et al. 1995) or in drug-free patients using $15 \mathrm{mg}, 25 \mathrm{mg}, 50 \mathrm{mg}, 100 \mathrm{mg}$, and $250 \mathrm{mg}$ daily consecutively for 4 days (van Berckel et al. 1996). Both studies reported a selective reduction in negative symptoms, most prominent at dosages of 50 mg (Goff et al. 1996) or 100 mg (van Berckel et al. 1996). D-cycloserine (10 and $30 \mathrm{mg}$ ), when added to the typical antipsychotic molindole (Rosse et al. 1996) did not induce symptomatic changes. Similarly when D-cycloserine was added to clozapine in dosages of $5 \mathrm{mg}, 15$ $\mathrm{mg}, 50 \mathrm{mg}$, and $250 \mathrm{mg}$ consecutively for 2 weeks no changes were found (Goff et al. 1996). Interestingly, 250 mg D-cycloserine daily, in addition to typical antipsychotics, was found to exacerbate psychotic symptoms, such as hallucinations, conceptual disorganization, and aggressive behavior in four of seven schizophrenic patients, although one patient with predominantly negative symptoms showed some improvement (Cascella et al. 1994). Moreover, the treatment of 10 psychotic patients with D-cycloserine in dosages between $500 \mathrm{mg}$ and $3000 \mathrm{mg}$ daily induced an exacerbation of hallucinations and paranoia in seven patients (Simeon et al. 1970).

Thus, in two open studies beneficial effects of D-cycloserine in schizophrenia have been reported, with effective dosages ranging from $50 \mathrm{mg}$ to $100 \mathrm{mg}$ daily, but worsening in doses of $250-500 \mathrm{mg}$ daily. Therefore, this study was designed to evaluate the effects of $100 \mathrm{mg}$ D-cycloserine, when added to typical antipsychotics in a placebo-controlled, double-blind, parallel design. In addition, the effects of D-cycloserine on LH secretion was determined because LH secretion induced by D-cycloserine may be a model for in vivo human NMDA receptor function (van Berckel et al. 1998b). 


\section{MATERIALS AND METHODS}

\section{Patients}

Twenty-six patients who met DSM-IV criteria for schizophrenia and were free of other axis 1 diagnoses were recruited (Table 1). All patients were between the ages of 18 and 60 years, had normal results on laboratory and physical examinations, including ECG. Patients who were using street drugs or abused alcohol were excluded. Subjects were interviewed by two raters concurrently using the Comprehensive Assessment of Symptoms and History interview (CASH; Andreasen 1985). All patients were assessed using the Mini Mental State Examination. On the basis of the interview and chart review of the patient's file, independent DSM-IV diagnoses were assigned by each rater, a consensus diagnosis was reached, which was then reviewed by a senior psychiatrist. Patients were maintained on clinically determined typical antipsychotic and anticholinergic medication and did not use antidepressants. Antipsychotic medication had been stable for at least 3 months. All patients scored at least "moderately severe" on the Clinical Global Impression Scale (CGI), despite continuous treatment with antipsychotics for at least 6 months. Furthermore, patients had to exhibit negative symptoms, defined as scores of at least "moderate" on two items of the negative subscale of the PANSS (Kay et al. 1987). These negative symptoms had been present for at least 6 months preceding the trial as evaluated by previous clinical assessments. In order to differentiate between "primary" and "secondary" negative symptoms, patients with concurrent diagnosis of depression in the $\mathrm{CASH}$ and patients with a high level of extrapyramidal symptoms (EPS) as defined as a score of "quite severe" or higher on the "global clinical impression of dyski- netic movements" and "global clinical impression of parkinsonism" of the Extrapyramidal Symptoms Rating Scale (ESRS) were excluded.

After providing written informed consent, patients were randomly assigned to the D-cycloserine or placebo group by the pharmacist of the University Hospital Utrecht. Patients, raters, and ward-staff were blind to treatment. Patients received either one capsule containing $50 \mathrm{mg}$ D-cycloserine twice daily or identical looking placebo for 8 weeks. Just before the start of treatment and subsequently every 2 weeks for 8 weeks, patients were evaluated by two raters concurrently using the PANSS and the CGI. The intraclass correlation for the independent total PANSS scores of both raters was $>0.9$. A team of four trained raters was assigned to each patient. Only these raters were allowed to interview the patient during the trial, in order to reduce interrater variability. In addition, every 2 weeks the ESRS was used to assess extrapyramidal side effects and dyskinesia (Chouinard et al. 1980). Finally, D-cycloserine and LH plasma levels were determined every 2 weeks 12 hours after the last drug administration. Blood samples were collected in 10-ml plastic tubes containing EDTA. They were centrifuged (10 minutes at $3000 \mathrm{rev} /$ minute at $4^{\circ} \mathrm{C}$ ). Plasma was transferred into plastic tubes and stored at $-80^{\circ} \mathrm{C}$ until the time of the assay.

\section{Assessment of D-Cycloserine Plasma Levels}

D-cycloserine plasma levels were determined using a fully automatic liquid chromatographic analysis with fluorescence detection as has been previously described (van Berckel et al. 1997).

Table 1. Patient Characteristics

\begin{tabular}{|c|c|c|c|}
\hline & D-cycloserine & Placebo & Significance \\
\hline Number $(n)$ & 13 & 13 & \\
\hline Age (years) & $45 \pm 6$ & $44 \pm 9$ & N.S. \\
\hline \multicolumn{4}{|l|}{ Sex } \\
\hline Male $(n)$ & 10 & 12 & N.S. \\
\hline Female $(n)$ & 3 & 1 & N.S. \\
\hline B.M.I. $^{a}$ & $26 \pm 6$ & $24 \pm 4$ & N.S. \\
\hline Inpatients ( $n)$ & 10 & 9 & \\
\hline Outpatients $(n)$ & 3 & 4 & \\
\hline Anticholinergics $(n)$ & 2 & 3 & N.S. \\
\hline Duration of illness (years) & $26 \pm 8$ & $22 \pm 10$ & N.S. \\
\hline Duration of hospitalization (years) & $20 \pm 12$ & $15 \pm 14$ & N.S. \\
\hline Hospitalizations $(n)$ & $4 \pm 2$ & $3 \pm 1$ & N.S. \\
\hline Duration last hospitalization (years) & $15 \pm 12$ & $13 \pm 13$ & N.S. \\
\hline Antipsychotic dose ${ }^{b}$ & $57 \pm 47$ & $38 \pm 23$ & N.S. \\
\hline Mini Mental State score & $25 \pm 6$ & $27 \pm 5$ & N.S. \\
\hline
\end{tabular}

\footnotetext{
${ }^{a}$ Body Mass Index.

${ }^{b}$ In mg haldol per week.
} 


\section{Neuroendocrine Measurements}

At the end of all of the tests of one subject, all measurements were carried out in one assay, in order to avoid inter-assay variation, by a technician blind to the sequence of treatment. Luteinizing hormone was measured with a fully automated immunoassay, AxSYM (Abbott Laboratories, Abbott Park, IL, USA) according to the instructions of the manufacturer. Calibrators were referenced to the WHO First International Reference Preparation 68/40. Intra-assay variation coefficients were $5.5,6.6$, and $8.3 \%$ respectively at $4.7,40$, and $83 \mathrm{IU} / 1$.

\section{Statistical Analysis}

Behavioral assessments, D-cycloserine plasma levels, and LH plasma levels were analyzed by means of analysis of variance (ANOVA) with repeated measurements with the baseline value as co-variate. Time, treatment and [treatment $x$ time] interaction were evaluated. If a drop-out occurred, behavioral measurements were analyzed on an intention to treat basis, with the last item carried forward.

\section{RESULTS}

\section{D-cycloserine Tolerance and Plasma Levels}

D-cycloserine was well tolerated and did not induce clear, clinically apparent side effects. D-cycloserine administration induced an increase in D-cycloserine plasma levels that was stable during the trial (mean $=23.7 \mu \mathrm{M}$, $\mathrm{SD}=12.2$, range mean values between $29.3 \mu \mathrm{M}$ and $20.3 \mu \mathrm{M}$ ) (see Figure 1). There were no statistically significant differences in D-cycloserine plasma concentration on the 2, 4, 6 , and 8 weeks time points.

\section{Behavioral Measurements and Patient Characteristics}

Twenty-six patients entered the trial, 25 patients completed the 8-week treatment period. One patient dropped out after 6 weeks of treatment in the D-cycloserine group. Patient characteristics are presented in

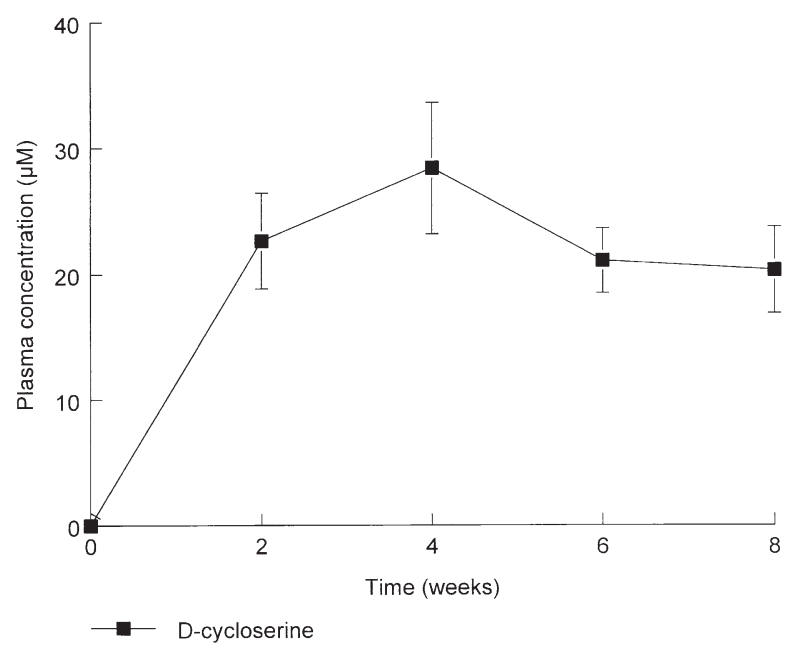

Figure 1. D-cycloserine plasma levels $(\mu \mathrm{M})$ of 12 patients with schizophrenia treated with $100 \mathrm{mg}$ D-cycloserine during 8 weeks (mean values \pm standard error).

Table 1 and baseline behavioral ratings in Table 2. As shown in Table 2, patients in the D-cycloserine group had statistically significantly higher PANSS negative symptoms scores than patients in the placebo group. The groups did not differ in baseline scores of the total, positive, and general psychopathology scales of the PANSS or the CGI.

Concerning PANSS ratings, total PANSS scores (Figure $2 \mathrm{~A}$ ) showed a statistically significant mean increase on D-cycloserine treatment $(\mathrm{F}[1 ; 23]=7.2, p=$ .013) but no effect was found on the factors time ( $\mathrm{F}[3 ; 72]$ $=0.48, p=.689)$ or [treatment $\times$ time] interaction $(\mathrm{F}[3 ; 72]=1.52, p=.217)$. The most prominent effect was an increase in the score of the positive subscale in the D-cycloserine group (Figure 2B). A statistically significant mean effect of D-cycloserine treatment $(\mathrm{F}[1 ; 23]=$ 5.96, $p=0.023)$ and [treatment $\times$ time] interaction, $(\mathrm{F}[3 ; 72]=2.78, p=.047)$ was observed. Mean positive symptoms ratings were increased compared to baseline at week $4(4.5 \%)$ and week $6(8.2 \%)$ and were at baseline values at week 2 and week 8 . Analysis performed on the individual items of the positive subscale of the PANSS revealed a statistically significant increase in the

Table 2. Baseline Behavioral Ratings

\begin{tabular}{lccc}
\hline & D-cycloserine & Placebo & Significance \\
\hline PANSS & & & \\
$\quad$ Total & $96.6 \pm 13.2$ & $88.7 \pm 10.8$ & N.S. \\
Positive & $20.7 \pm 3.4$ & $18.1 \pm 4.0$ & N.S. \\
Negative & $28.7 \pm 5.6$ & $21.7 \pm 3.8$ & $\mathrm{p}=0.045$ \\
$\quad$ General & $47.3 \pm 7.6$ & $45.9 \pm 6.9$ & N.S. \\
CGI & $5.0 \pm 0.8$ & $4.7 \pm 0.9$ & N.S. \\
$\quad$ Severity of illness & & \\
\hline
\end{tabular}


$2 A$

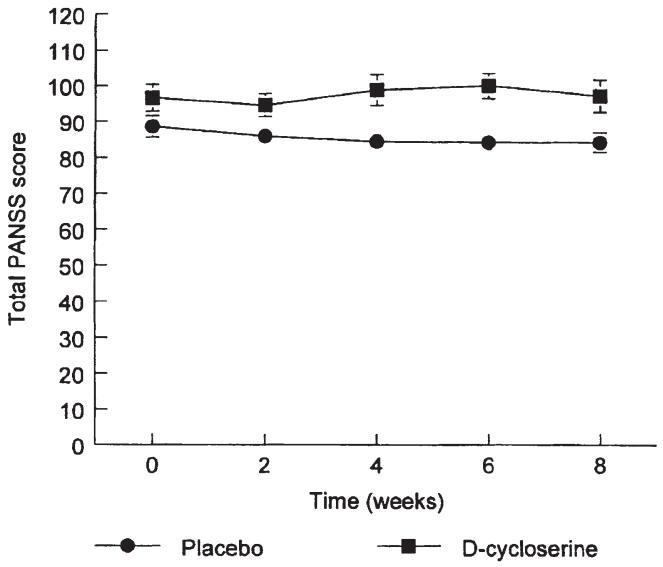

2C

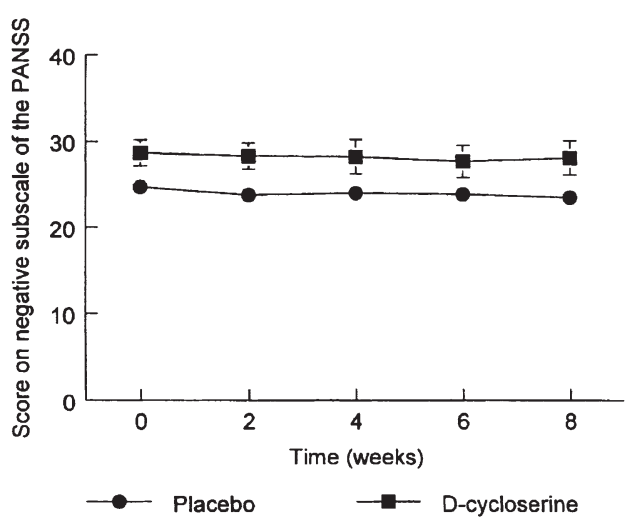

2B

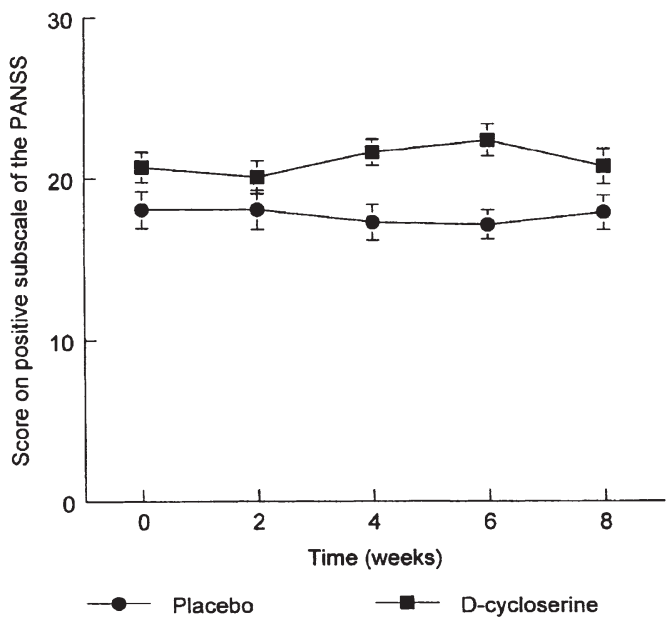

$2 \mathrm{D}$

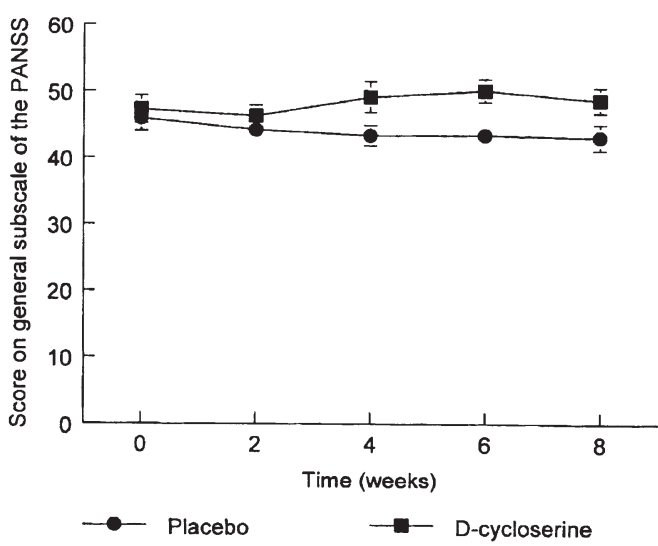

Figure 2. Total PANSS scores (2A) and scores on the positive subscale (2B), the negative subscale (2C), and the general psychopathology subscale of the PANSS of patients with schizophrenia treated with D-cycloserine (13) or placebo (13) (mean values \pm standard error).

D-cycloserine group on the items delusions $(\mathrm{F}[3 ; 72]=$ 3.3, $p=0.025$ [treatment $\times$ time interaction]), grandiosity $(\mathrm{F}[3 ; 72]=3.12, p=.031$ [treatment $\times$ time interaction]) and hostility $(\mathrm{F}[3 ; 72]=2.81, p=.045$ [treatment $\times$ time interaction]). Analysis of the scores on the negative subscale (Figure $2 \mathrm{C}$ ) revealed no statistically significant mean effect of D-cycloserine treatment $(\mathrm{F}[1 ; 23]=0.39$, $p=.541)$ or [treatment $\times$ time] interaction $(\mathrm{F}[3 ; 72]=$ $0.17, p=.921)$.

Furthermore, an increase in scores on the general psychopathology subscale was observed (Figure 2D). A statistically significant effect of D-cycloserine treatment $(\mathrm{F}[1 ; 23]=8.15, p<=.009)$ but not of [treatment $\times$ time interaction] $(\mathrm{F}[3 ; 72]=2.14, p=.103)$ was found.
D-cycloserine did not induce a change in the item Severity of Illness of the CGI $(\mathrm{F}[1 ; 23]=0.42, p=.524)$ however D-cycloserine treatment caused a slight increase in scores on the Global Impression item, indicating a global worsening, which just failed to reach statistical significance $(\mathrm{F}[1 ; 24]=4.16, p=.053)$. D-cycloserine did not alter scores on the dyskinesia subscale $(\mathrm{F}[1 ; 23]=$ $0.51, p=.48)$ or parkinsonism subscale $(\mathrm{F}[1 ; 23]=1.18$, $p=.29)$ of the ESRS.

During the trial, one female patient of the D-cycloserine group refused further treatment after 6 weeks because she said that "these pills made her crazy." In another patient, nurses reported an increase in delusions. However, this was accompanied by a beneficial increase 
in activity and social behavior to such an extent that nurses asked for the treatment to be continued, despite the increase in psychotic symptoms. Several caretakers mentioned that in some patients symptoms reoccurred that had not been present for several years. For instance, in one male patient sexually inappropriate behavior toward female patients became apparent, a behavior he had not exhibited for almost 10 years.

\section{LH Secretion}

LH plasma levels were evaluated in 10 male patients in the D-cycloserine group and 8 male patients in the placebo group. LH levels were only determined in males to exclude the cyclic variation in LH plasma levels occurring in females. D-cycloserine treatment did not change LH secretion compared to placebo $(\mathrm{F}[1 ; 14]=$ $2.14, p=.166$; Figure 3).

\section{DISCUSSION}

This study reports that $100 \mathrm{mg}$ of D-cycloserine daily induced a moderate increase in psychotic symptoms and general psychopathology compared to placebo when it was added to conventional antipsychotics in chronic schizophrenic patients exhibiting prominent negative symptoms. D-cycloserine failed to change negative symptoms and had no effect on extrapyramidal symptoms. In addition D-cycloserine treatment had no effect on plasma levels of luteinizing hormone.

Deterioration of schizophrenic symptoms during D-cycloserine treatment was reported in two prior open studies, as was indicated earlier. The first study described the effects of D-cycloserine in dosages between $500 \mathrm{mg} /$ day and $3000 \mathrm{mg} /$ day (Simeon et al. 1970). An exacerbation of hallucinations and paranoia was re-

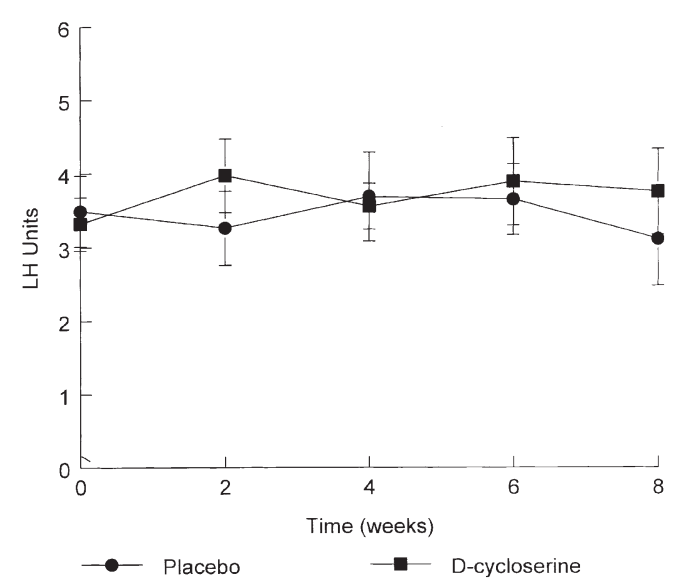

Figure 3. LH plasma levels during 8 weeks of D-cycloserine treatment with $100 \mathrm{mg}$ D-cycloserine or placebo of 10 male patients in the $\mathrm{D}$-cycloserine group and 8 male patients in the placebo group (mean values \pm standard error). ported in about $70 \%$ of the patients who were treated with typical antipsychotics. It was stated that blood levels higher than 45 microgram $/ \mathrm{ml}$ were associated with psychomotor excitement. We found that D-cycloserine exacerbated psychotic symptoms in schizophrenia at blood levels 15 times lower (i.e., between 2.0 and 2.9 microgram $/ \mathrm{ml}$ ). The second study reported that $250 \mathrm{mg}$ D-cycloserine daily in addition to conventional antipsychotics aggravated psychotic symptoms in four of seven patients with chronic schizophrenia (Cascella et al. 1994). Comparison of this study with our previous report (van Berckel et al. 1996) and the only other report currently available in which beneficial effects of D-cycloserine on the negative symptoms of schizophrenia were described (Goff et al. 1996) is hampered by differences in design (increasing dosages versus fixed dose), treatment regime (drug-free patients versus patients treated with neuroleptics), and inclusion criteria. In the previous study, we reported a decrease in the score on the negative subscale of the PANSS after a 4-day treatment with $100 \mathrm{mg}$ of D-cycloserine, following 4-day treatment periods with $15 \mathrm{mg}, 25 \mathrm{mg}$, and $50 \mathrm{mg}$ of D-cycloserine, respectively. Although the behavioral changes were the most prominent at the 100-mg dose, corresponding to a plasma concentration of around $20 \mu \mathrm{M}$ (around 2.0 microgram $/ \mathrm{ml}$ ), it cannot be ruled out that these changes were the result of the (lingering) effects of D-cycloserine at the lower dosages of $15 \mathrm{mg}, 25 \mathrm{mg}$, and $50 \mathrm{mg}$. This may also explain why D-cycloserine has been reported to exhibit beneficial effects in a lower dose range (i.e., around $50 \mathrm{mg}$ ) (Goff et al. 1996). Thus, the plasma levels of D-cycloserine in the current study may have been too high resulting in competition of D-cycloserine with the endogeneous agonist (and therefore in effect acting as a functional antagonist at the glycine recognition site of the NMDA receptor). Indeed, other NMDA antagonists, like PCP and ketamine, have been shown to induce an exacerbation of disease related psychotic symptoms in schizophrenic patients (Luby et al. 1959, 1962; Lahti et al. 1995; Malhotra et al. 1997a, 1997b). The notion that D-cycloserine may be devoid of agonistic activity at NMDA receptors in this dose and design is supported by the lack of effect of D-cycloserine on LH secretion, as LH secretion in humans has been suggested to be sensitive to the agonistic effects of D-cycloserine (van Berckel et al. 1998b) while it is not influenced by NMDA antagonists (van Berckel et al. 1998a). Although D-cycloserine did not ameliorate schizophrenic symptoms in this study, the fact that they actually worsened suggests that NMDA systems may be involved in the pathogenesis of schizophrenia.

Alternatively, the symptomatic exacerbation observed in this study could be explained by the fact that D-cycloserine was added to typical antipsychotics. These drugs interfere with NMDA-mediated neurotransmission. Indeed, in clinically effective concentrations, 
haloperidol can stimulate NMDA receptors (Banerjee et al. 1995), as can chlorpromazine and thioridazine (Lidsky et al. 1997). Moreover, data from electrophysiological studies, using whole cell voltage clamp in cultured hippocampal neurons suggest that haloperidol may act as a partial agonist at the glycine recognition site of the NMDA receptor (Fletcher and Macdonald 1993). In addition, in rats, chronic antipsychotic treatment has been shown to selectively reduce the ability of glycine, but not of NMDA or spermine to enhance NMDA receptor activity. This indicates that antipsychotics induce a dysregulation specifically at the glycine recognition site of the NMDA receptor (McCoy and Richfield 1996). Although the clinical importance of this interference at the NMDA receptor still remains to be elucidated, the interaction with NMDA mediated neurotransmission could be one of the mechanisms through which antipsychotics have their antipsychotic effects and may be involved in the EPS liability of these drugs. Therefore, it can be hypothesized that if D-cycloserine competes with the antipsychotics at the level of the glycine recognition site, this may lead to a diminished antipsychotic efficacy and, in addition, could reduce EPS. Finally, the patients in the D-cycloserine treatment group had higher baseline scores on the negative and positive symptoms subscales of the PANSS and higher dosages of antipsychotics. Although the difference between baseline ratings on the positive subscale of the PANSS was small, we cannot exclude the possibility that the increase in psychosis in the D-cycloserine treatment group may be due to a difference in psychosis sensitivity between the two groups.

In conclusion, the therapeutic window of D-cycloserine is likely to be small and may be too narrow to be clinically useful. Probably only dosages of around 50 mg will prove effective, although the only double-blind study currently available that describes the effects of 10 $\mathrm{mg}$ and $30 \mathrm{mg}$ of D-cycloserine included only three and six patients, respectively. Thus, further placebo-controlled studies with lower dosages of D-cycloserine, preferably in drug-free patients, are necessary to evaluate if D-cycloserine is of use for the treatment of patients with schizophrenia until new drugs become available that penetrate the blood-brain barrier and have a higher potency at the glycine recognition site of the NMDA receptor.

\section{ACKNOWLEDGMENTS}

The authors thank J.E. Braams, A.A. Klompmakers and S. de Graaf for their technical assistance; A.F.A.M. Schobben, Ph.D. and M.A. Blankenstein, Ph.D. for their critical advice and assistance. All the psychiatrists and nurses of Psychiatrisch Ziekenhuis Veldwijk, Psychiatrisch Ziekenhuis Amsterdam, and Riagg Flevoland are greatly acknowledged for their invaluable support.

\section{REFERENCES}

Andreasen NC (1985): Comprehensive Assessment of Symptoms and History (CASH). Iowa City, University of Iowa

Banerjee SP, Zuck LG, Yablonsky Alter E, Lidsky TI (1995): Glutamate agonist activity: Implications for antipsychotic drug action and schizophrenia. Neuroreport 6:2500-2504

Cascella NG, Macciardi F, Cavallini C, Smeraldi E (1994): D-Cycloserine adjuvant therapy to conventional neuroleptic treatment in zchizophreania: An open-label study. J Neural Transm-Gen Sect 95:105-111

Chessell IP, Procter AW, Francis PT, Bowen DM (1991): D-cycloserine, a putative cognitive enhancer, facilitates activation of the N-methyl-D-aspartate receptor-ionophore complex in Alzheimer brain. Brain Res 565:345-348

Chouinard G, Ross-Chouinard A, Annable L, Jones BD (1980): Extrapyramidal Symptom Rating Scale. Can Neurol Sci 7:3,233

Emmett MR, Mick SJ, Cler JA, Rao TS, Iyengar S, Wood PL (1991): Actions of D-cycloserine at the N-methylD-aspartate-associated glycine receptor site in vivo. Neuropharmacology 30:1167-1171

Fletcher EJ, MacDonald JF (1993): Haloperidol interacts with the strychnine-insensitive glycine site at the NMDA receptor in cultured mouse hippocampal neurones. Eur J Pharmacol 235:291-295

Gao XM, Chen LW, Tamminga CA (1997): Blockade of phencyclidine- and MK-801 induced regional zif268 mRNA expression. Schizophrenia Research 24:76

Goff DC, Tsai GC, Manoach DS, Coyle JT (1995): Dose-finding trial of D-cycloserine added to neuroleptics for negative symptoms in schizophrenia. Am J Psychiatry 152:1213-1215

Goff DC, Tsai GC, Manoach DS, Flood J, Darby DG, Coyle JT (1996): D-cycloserine added to clozapine for patients with schizophrenia. Am J Psychiatry 153:1628-1630

Henn FA (1995): The NMDA receptor as a site for psychopathology-primary or secondary role? Arch Gen Psychiatry 52:1008-1010

Heresco-Levy U, Javitt DC, Ermilov M, Mordel C, Horowitz A, Kelly D (1996): Double-blind, placebo-controlled, crossover trial of glycine adjuvant therapy for treatmentresistant schizophrenia. Br J Psychiatry 169:610-617

Hood WF, Compton RP, Monahan JB (1980): D-cycloserine: A ligand for the N-methyl-D-aspartate coupled glycine receptor has partial agonist characteristics. Neurosci Lett 98:91-95

Ishimaru M, Kurumaji A, Toru M (1994): Increases in strychnine-insensitive glycine binding sites in cerebral cortex of chronic schizophrenics: Evidence for glutamate hypothesis. Biol Psychiatry 35:84-95

Javitt DC, Zylberman I, Zukin SR, Heresco-Levy U, Lindenmayer J (1994): Amelioration of negative symptoms in schizophrenia by glycine. Am J Psychiatry 151:1234-1236

Javitt DC, Zukin SR (1991): Recent advances in the phencyclidine model of schizophrenia. Am J Psychiatry 148:1301-1308

Kay SR, Fiszbein A, Opler LA (1987): The Positive and Nega- 
tive Syndrome Scale (PANSS) for schizophrenia. Schizophr Bull 13:261-276

Krystal JH, Karper LP, Seibyl JP, Freeman GK, Delaney R, Bremner JD, Heninger GR, Bowers MB Jr, Charney DS (1994): Subanesthetic effects of the noncompetitive NMDA antagonist, ketamine, in humans: Psychotomimetic, perceptual, cognitive, and neuroendocrine responses. Arch Gen Psychiatry 51:199-214

Lahti AC, Koffel B, Laporte D, Tamminga CA (1995): Subanesthetic doses of ketamine stimulate psychosis in schizophrenia. Neuropsychopharmacology 13:9-19

Lidsky TI, Yablonskyalter E, Zuck LG, Banerjee SP (1997): Antipsychotic drug effects on glutamatergic activity. Brain Res 764:46-52

Luby ED, Cohen BD, Rosenbaum G, Gottlieb JS, Kelly R (1959): Study of a new schizophrenomimetic drug-Sernyl. AMA Arch Neurol Psychiat 81:363-369

Luby ED, Gottlieb JS, Cohen BD, Rosenbaum G, Domino EF (1962): Model psychoses and schizophrenia. Am J Psychiatry 199:61-67

Malhotra AK, Adler CM, Kennison SD, Elman I, Pickar D, Breier A (1997a): Clozapine blunts N-methyl-D-aspartate antagonist-induced psychosis: A study with ketamine. Biol Psychiatry 42:664-668

Malhotra AK, Pinals DA, Adler CM, Elman I, Clifton A, Pickar D, Breier A (1997b): Ketamine-induced exacerbation of psychotic symptoms and cognitive impairment in neuroleptic-free schizophrenics. Neuropsychopharmacology 17:141-150

McCoy L, Richfield EK (1996): Chronic antipsychotic treatment alters glycine-stimulated NMDA receptor binding in rat brain. Neurosci Lett 213:137-141

Monahan JB, Handelmann GE, Wood WF, Cordi AA (1989): D-cycloserine, a positive modulator of the N-methylD-aspartate receptor, enhances performance of learning tasks in rats. Pharmacol Biochem Behav 34:649-653

Nishikawa T, Takashima M, Toru M (1983): Increased $\left[{ }^{3} \mathrm{H}\right]$ kainic acid binding in the prefrontal cortex in schizophrenia. Neurosci Lett 40:245-250

Olney JW, Farber NB (1995): Glutamate receptor dysfunction and schizophrenia. Arch Gen Psych 52:998-1007

Paschen W (1996): Glutamate excitotoxicity in transient global cerebral ischemia. Acta Neurobiol Exp 56:313-322

Priestley T, Laughton P, Myers J, Le Bourdelles B, Kerby J, Whiting PJ (1995): Pharmacological properties of recom- binant human N-methyl-D-aspartate receptors comprising NR1a/NR2A and NR1a/NR2B subunit assemblies expressed in permanently transfected mouse fibroblast cells. Mol Pharmacol 48:841-848

Quartermain D, Mower J, Rafferty MF, Herting RL, Lanthorn TH (1994): Acute but not chronic activation of the NMDA-coupled glycine receptor with D-cycloserine facilitates learning and retention. Eur J Pharmacol 257:7-12

Rosse RB, Faymccarthy M, Kendrick K, Davis RE, Deutsch SI (1996): D-cycloserine adjuvant therapy to molindone in the treatment of schizophrenia. Clin Neuropharmacol 19:444-450

Simeon J, Fink M, Itil TM, Ponce D (1970): d-Cycloserine therapy of psychosis by symptom provocation. Comp Psychiatry 11:80-88

Toru M, Watanabe S, Shibuya H, Nishikawa T, Noda K, Mitsushio H, Ickikawa H, Kurumaji A, Takashima M, Mataga N, Ogawa A (1988): Neurotransmitters, receptors and neuropeptides in post-mortem brains of chronic schizophrenic patients. Acta Psychiatr Scand 78:121-137

Tsai G, Passani LA, Slusher BS, Carter R, Baer L, Leinman JE, Coyle JT (1995): Abnormal excitatory neurotransmitter metabolism in schizophrenic brains. Arch Gen Psychiatry 52:829-836

Van Berckel BNM, Hijman R, van der Linden JA, Westenberg HGM, van Ree JM, Kahn RS (1996): Efficacy and tolerance of D-cycloserine in drug-free schizophrenic patients. Biol Psychiatry 40:1298-1300

Van Berckel BNM, Lipsch C, Timp S, Gispen de Wied C, Wynne H, van Ree JM, Kahn RS (1997): Behavioral and neuroendocrine effects of the partial NMDA agonist D-cycloserine in healthy subjects. Neuropsychopharmacology 16:317-324

Van Berckel BNM, Oranje B, van Ree JM, Verbaten MN, Kahn RS (1998a): The effects of low dose ketamine on sensory gating, neuroendocrine secretion and behavior in healthy human subjects. Psychopharmacology 137: 271-281

Van Berckel BNM, Lipsch C, Gispen de Wied CC, Wynne HJ, Blankenstein PA, Vanree JM, Kahn RS (1998b): The partial NMDA agonist D-cycloserine stimulates LH secretion in healthy volunteers. Psychopharmacology 138: 190-197

Walker WC, Murdoch, JM (1957): Cycloserine in the Treatment of Pulmonary Tuberculosis. A Report on Toxicity. Tubercle, Lond 38:297 